INDEPENDENT JOURNAL OF MANAGEMENT \& PRODUCTION (IJM\&P)

http://www.ijmp.jor.br

v. 6, n. 4, October - December 2015

ISSN: 2236-269X

DOI: 10.14807/ijmp.v6i4.356

\title{
AN INTEGRATED CONCEPTUAL FRAMEWORK FOR RFID ENABLED HEALTHCARE
}

\author{
Gaurav Gupta \\ Indian Institute of Management Calcutta, Indian \\ E-mail: gauravg13@email.iimcal.ac.in \\ Tithishri Kundu \\ Medical College, Kolkata, India \\ E-mail: tithishrikundu@gmail.com \\ Appachu Appanna Codanda \\ Indian Institute of Management Calcutta, Indian \\ E-mail: codandaaa2016@email.iimcal.ac.in
}

Submission: 03/07/2015

Accept: 22/07/2015

\section{ABSTRACT}

Radio frequency identification (RFID) technology is a wireless communication technology that facilitates automatic identification and data capture without human intervention. Since 2000s, RFID applications in the health care industry are increasing. RFID has brought many improvements in areas like patient care, patient safety, equipment tracking, resource utilization, processing time reduction and so on. On the other hand, often deployment of RFID is questioned on the issues like high capital investment, technological complexity, and privacy concerns. Exploration of existing literature indicates the presence of works on the topics like asset management, patient management, staff management, institutional advantages, and organizational issues. However, most of the works are focused on a particular issue. Still now, scholarly attempts to integrate all the facades of RFID-enabled healthcare are limited. In this paper, we propose a conceptual framework that represents the scope for implementation of this technology and the various dimensions of RFID-enabled healthcare and demonstrate them in detail. Also, we have discussed the critical issues that can prove to be potential 
INDEPENDENT JOURNAL OF MANAGEMENT \& PRODUCTION (IJM\&P)

http://www.ijmp.jor.br

v. 6, n. 4, October - December 2015

ISSN: 2236-269X

DOI: 10.14807/ijmp.v6i4.356

barriers to its successful implementation and current approaches to resolving these. We also discuss some of the regulatory initiatives encouraging its adoption in the healthcare industry. Also, we have highlighted the future research opportunities in this domain.

Keywords: RFID; healthcare; conceptual framework

\section{INTRODUCTION}

Radio Frequency Identification (RFID), originated in 1940s, can be defined as an electronic tagging technology designed to assign an electronic identity to any object with the help of radio waves. It is deployed in various industries like manufacturing, retail, education, food, printing, pharmaceutical, healthcare, and many others (HONG et al., 2011; HOU; HUANG, 2006; WANG; CHEN; ONG, 2006) Since 2000s, there is an increasing trend to integrate RFID technology in the healthcare industry to combat problems like preventing drug counterfeiting, tracking medical equipment, better patient management, efficient workflow management (KOLESZAR, 2004). Especially the revised mandate issued by Wal-Mart in 2003 triggered interest among researchers and practitioners in the deployment of RFID in both logistics and healthcare. In a recent report titled Market Opportunity for RFID Smart Cabinet Systems in Healthcare (2015) by Frost \& Sullivan, RFID market for healthcare and pharmaceuticals in Europe was estimated to be $12 \%$ of the total market for RFID technology across industries.

Existing literature indicates the significant number of scholarly works on the issues like asset management (BRITTON, 2007; KIM et al., 2008; PULLEN; ATKINSON; TUCKER, 2000) staff management (WANG; CHIANG, 2010), patient management (RHODES; RESNICK, 2005), institutional advantages (MEHRJERDI, 2010; WAMBA, 2012), privacy issues (KATZ; RICE, 2009; SMITH, 2006; XIAO et al., 2006), organizational issues (BRADING, 2009; TING et al., 2011), and so on. However, most of the studies have dealt with a particular issue. A few attempts try to incorporate all the dimensions of RFID using a single framework. In this paper, we have proposed a framework that incorporates all the dimensions of RFID-enabled healthcare like the scope of the applications, functional aspects, barriers, and Advantages. We have presented several real life examples of successful 
INDEPENDENT JOURNAL OF MANAGEMENT \& PRODUCTION (IJM\&P)

http://www.ijmp.jor.br

v. 6, n. 4, October - December 2015

ISSN: 2236-269X

DOI: 10.14807/ijmp.v6i4.356

implementation of RFID. Also, we have provided the future research opportunities lie in the context of RFID-enabled healthcare.

The remainder of this paper is organized as follows. In the next section, we present a summary of RFID technology. Then we propose a conceptual framework and detailed demonstration of all its dimensions. We then discuss the critical issues related to RFID deployment and how they can be handled. The paper concludes by discussing the contribution and future research avenues.

\subsection{RFID Technology}

Radio frequency identification (RFID) technology is a wireless communication technology that facilitates automatic identification and data capture without human intervention. It has the advantage of being able to capture information without the need for the identification module and the probe to be in the line of sight. This allows for its implementation in various non-conventional usages like invasive RFID chips for perpetual patient identification and monitoring. An RFID system comprises three components:

- Tags - It consists of a transponder with a digital memory device. On the basis of powering techniques, it can be classified into three categories: active tags, passive tags, and semi-passive tags. In an active RFID tag, the power source is embedded in it as an on-board battery. On the other hand, the signal of an external reader supplies power to the passive tags. The design of a semi-passive tag lies between active tag and passive tag where a passive tag must be turned on by a reader to transmit data despite the presence of embedded battery in it. A tag is used to store and transmit the information about the object it is attached with.

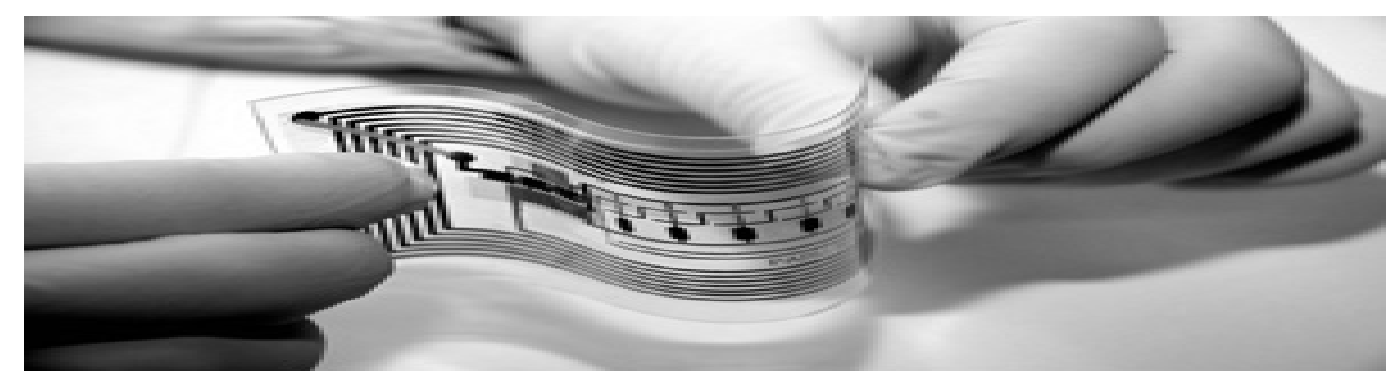

Figure 1: Medical RFID tag ${ }^{1}$

${ }^{1}$ Source: http://www.medgadget.com/2010/04/cheaper_rfid_printed_on_paper.html 
- Tag reader - Tag reader, often denoted as 'interrogator', contains a transceiver, decoder, and antenna. A tag reader is controlled by a microprocessor for communicating with the tags. The antenna attached with tag reader helps to transmit data from tags. The captured data is then passed to a computer through application software for further processing.

- Application Software - Application software is considered as the central controller of an RFID system. It allows users to actually tie electronic identity and to share the information with others (ATTARAN, 2006). Data collected from tags is passed through cable or wireless to host computer systems that can be any device, like laptop or desktop computer, mobile device, etc. Based on the intended function, this data is then processed by the relevant software application.

The pictorial diagram given below represents the function of RFID technology (WOOD; ALVAREZ, 2005):

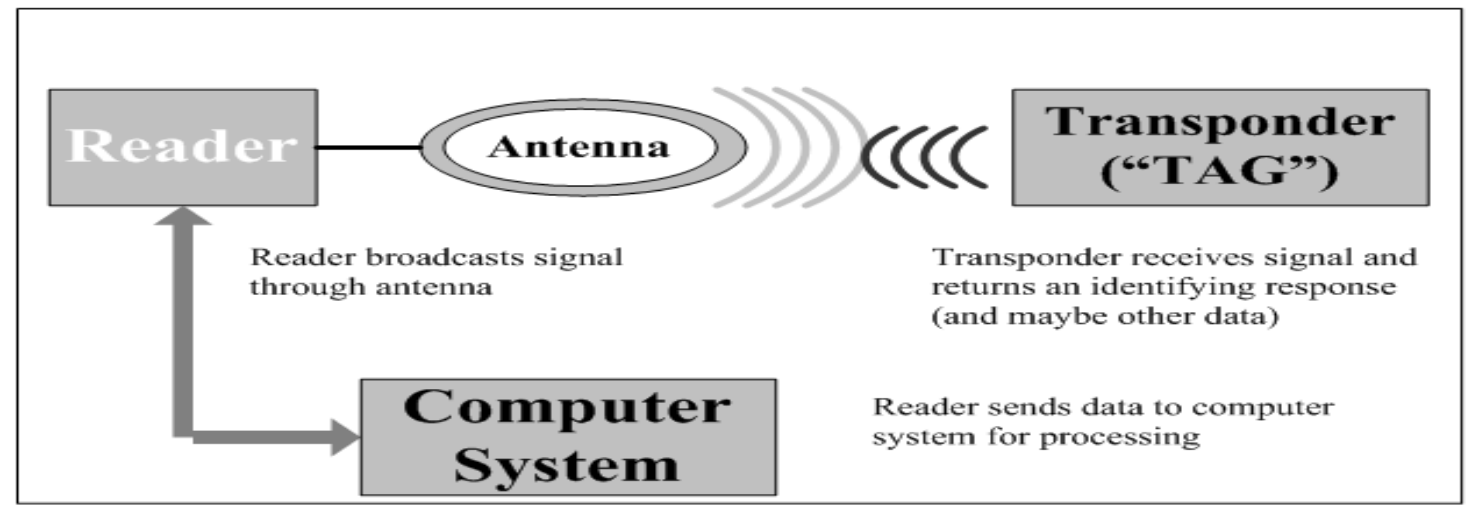

Figure 2: Function of RFID Technology

Source: Wood and Alvarez (2005)

\section{METHODOLOGY}

Based on extant scholarly works, here we propose an integrated conceptual framework for RFID-enabled healthcare. In this context, the scope of RFID technology is centrally positioned. It provides the natural synergistic progression to barcode-based tracking applications in healthcare functions. In addition, the framework comprises three different dimensions described below:

- Functional aspects- It signifies the various ways of RFID application.

- Barriers- Factors that hinder the implementation of RFID in this specific technology. 
- Advantages

The proposed framework is represented in figure 3. The scope of this technology along with its dimensions is discussed in detail in the following subsections.

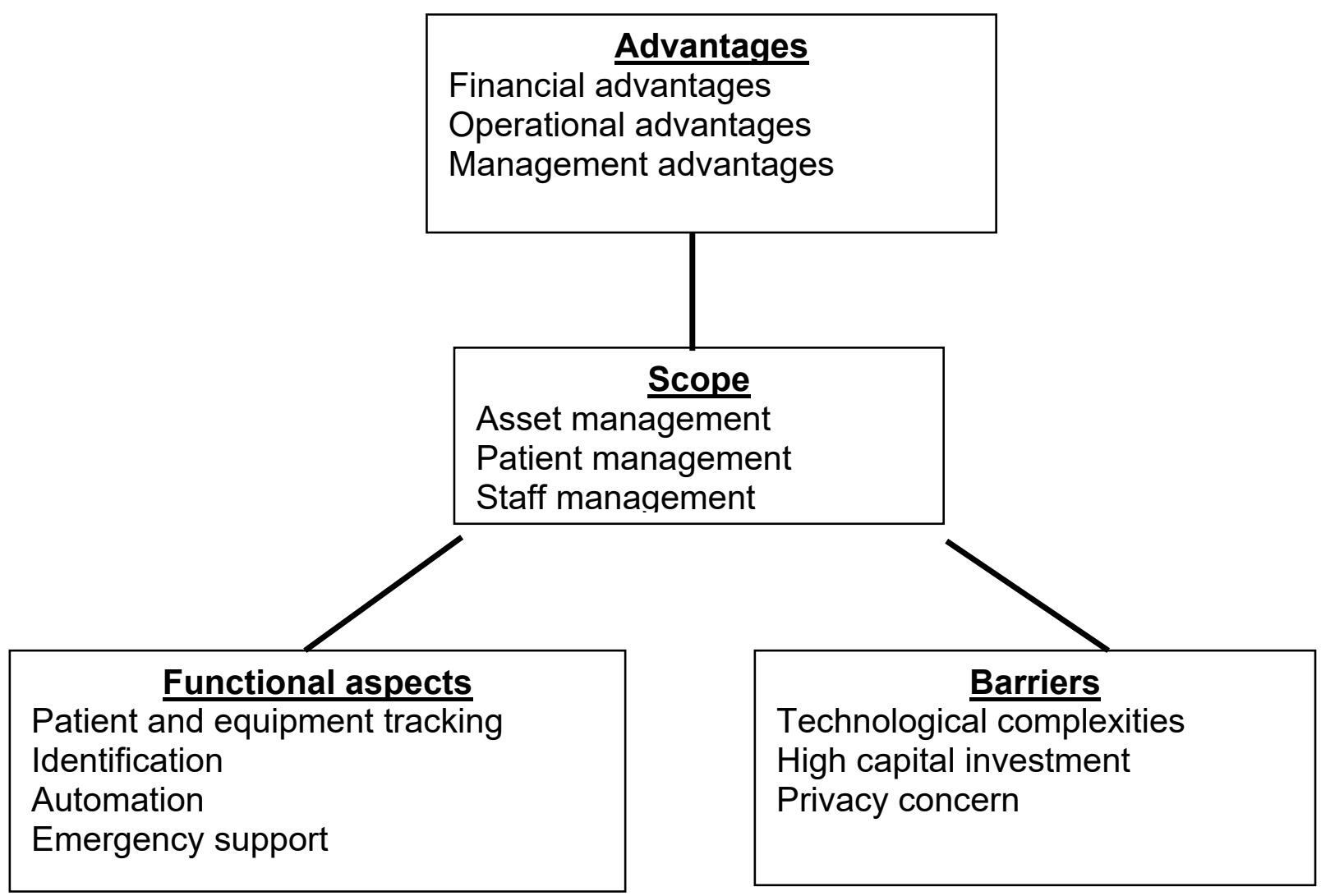

Figure 3: Conceptual framework of RFID-enabled healthcare systems

\subsection{Scope of the RFID-enabled health sector}

Exploration of existing literature reveals that there are three primary areas in the healthcare sector that show prevalent applications of RFID technology (WAMBA; ANAND; CARTER, 2013):

- Asset management

- Patient management

- Support staff and activity management

\subsection{Asset Management}

Asset management signifies the maintaining of the medical instruments in proper condition and providing the best service to the patients admitted in the 
INDEPENDENT JOURNAL OF MANAGEMENT \& PRODUCTION (IJM\&P)

http://www.ijmp.jor.br

v. 6, n. 4, October - December 2015

ISSN: 2236-269X

DOI: 10.14807/ijmp.v6i4.356

hospital. The condition of the medical equipment and patient service level are crucial factors in health care. RFID facilitates to maintain the service level and to track the conditions of equipment (YAO; CHU; LI, 2010).

According to a recent study, medicines manufactured in countries like Mexico and Columbia face a huge drug counterfeiting. Tampered drugs have an adverse effect on human health. Also, producers face an enormous economic loss due to the production of altered medicines. RFID helps to detect the presence of these unacceptable drugs.

\subsection{Patient management}

The employment of RFID technology has a significant impact in the area like Patient management. First of all, it helps to store patient history. Using the patient history, doctors easily can diagnose the suitable medicines for patients. In addition, many a times, change of doctor in charge does not affect the patients' treatment as new doctors can easily be aware of the patient's medical history.

Thus, it enhances patient recovery and safety. Several real life instances have justified this fact. In 2003, it showed its potential to combat with a dangerous infectious disease like SARS by providing better patient care in Taipei Medical University Hospital of Taiwan (WANG; CHEN; ONG, 2006).

Also, it facilitates to avoid mismatching and to provide security against theft especially in case of infant hospitals. Several critical issues like selection of proper surgical method, identification of patients to maintain proper drug dosage, identification of patients with impaired cognitive functioning, designing automated care intervention pathways etc. have been successfully handled using RFID.

\subsection{Support staff and activity management}

For staff management related issues, RFID brings in better efficiency in the workflow management by improving the labor productivity. Over allocation of workforce can raise the operational cost. On the other hand, under employment of the staffs can bring down the service level. The optimal number of support staff can be allocated to each station that leads to the optimal usage of human inventory.

RFID, when used in equipment tracking, helps nurses to cut down on treatment start time and thus helps deliver quality medical care. Better time utilization 
INDEPENDENT JOURNAL OF MANAGEMENT \& PRODUCTION (IJM\&P)

http://www.ijmp.jor.br

v. 6, n. 4, October - December 2015

ISSN: 2236-269X

DOI: 10.14807/ijmp.v6i4.356

by bringing down the processing time along with manual error reduction is also possible with the aid of this technology (ORANJE; SCHINDLER, 2009). Also, it manages medical waste efficiently by closely monitoring and tracking waste disposal procedures.

\subsection{Functional Aspects}

Our investigation into existing scholarly works reveals the presence of four important functional aspects of RFID technology applied in healthcare:

- Patient and medical equipment tracking

- Identification

- Automation design

- Emergency support system design

\subsection{Patient and medical equipment tracking}

Patient and medical equipment tracking is the most widely accepted application of RFID in healthcare. Usage of RFID tags, deployment of RFID-enabled robots for tracking patients, and medical equipment are already in practice in many developed nations. As an example, RFID tags bring down the specimen labeling errors in the pathology laboratory.

Also, loss due to theft is reduced because of tracking. Pathology labs require clerical work with regards to storage and systemic documentation of blood, urine samples, patient data and medical supplies. However, these pathology labs tend to remain inadequately staffed. RFID technology will benefit them by reducing manual documentation and also by making the inventory and data management more streamlined.

\subsection{Identification}

Prior to RFID, barcode-based inventory identification had inherent scanning problems that led to the creation of incorrect inventory records (DEHORATIUS; RAMAN, 2008). These manual processes also led to issues like medical examination mismatches and adverse drug events (ÇAKICl; GROENEVELT; SEIDMANN, 2011). Deployment of RFID encompasses preventing medical errors in critical scenarios like reconfirming the newborn identity, identifying the disaster victim identity, and so on. 
INDEPENDENT JOURNAL OF MANAGEMENT \& PRODUCTION (IJM\&P)

http://www.ijmp.jor.br

v. 6, n. 4, October - December 2015

ISSN: 2236-269X

DOI: 10.14807/ijmp.v6i4.356

Besides, security concerns can be improved through the implantation of an RFID tag into human molars.

RFID-enabled computer systems can also be utilized to perform a set of myriad actions to prevent medical errors. Medical errors are prevalent in administering right amount of dosage to patients, the type of medication, keeping track of medical history of the patient and delivery of appropriate medication to the correct patient at the proper time (PETERS; PETERS, 2007). RFID-enabled automated systems provide an efficient solution to substantially reduce such medical errors.

\subsection{Automation design}

Automated care and safety design is achieved using RFID. As an example, a self-pill-dispenser reminds patients about their medical dose (YAO; CHU; LI, 2010). From the perspective of workflow management, several manual works like the determination of patient discharge time, reservation for regular checkup can be achievable through automation.

In such a way, the system becomes more efficient and effective. Presently, the end customer reads the information mentioned on the labels of medical packages, and if the information is insufficient or incomprehensible, then it leads to confusion and hence medical error. RFID tags are increasingly being adopted by pharmaceutical companies in label design. This along with precise and appropriate drug information helps reduce errors in supply chain and also ensure proper drug information disbursal.

RFID tags ensure accurate data collection with minimal human intervention. This along with its continuous tracking and monitoring capability has also been used against counterfeiting of drugs in the pharmaceutical supply chain. Drug counterfeiting is a significant issue plaguing developing countries across the world where drug-counterfeiters exploit their lack of access to basic medication.

RFID technology is significantly secure and difficult to replicate, both at hardware and software levels, as compared to conventional batch tracking technologies. To crack down on counterfeiting, government agencies too are slowly adopting real time tracking using RFID technology to identify and track batch information of medicines right from their source. 


\subsection{Emergency support system design}

At the time of emergency or major casualties, RFID technology helps improve patient safety through appropriate surgical procedure adherence and hygiene monitoring. In addition, usage of RFID prevents the chance of blood type mismatch in the case of blood transfusion. Also, RFID helps ensure timely availability of medical equipment while simultaneously reducing the average inventory levels of such equipment. Critical care can thus be delivered immediately, thus helping save numerous lives.

\subsection{Advantages}

We have classified the advantages of RFID deployment in health care in three categories:

- Financial advantages

- Operational advantages

- Management advantages

\subsection{Financial advantages}

Implementation of RFID technology has reduced the labor cost, operating cost drastically through better maintenance of the equipment and proper inventory utilization. Also, manpower requirement goes down with the help of automated procedures. RFID technology also increases inventory certainty and hence enables lower average inventory leading to a reduction in operating costs (BAYSAN; USTUNDAG, 2013).

According to a recent study ${ }^{2}$, incorporation of RFID Kanban systems brings down overall inventory ordering, shortage, carrying and purchase costs by as much as $30 \%$. Even without changes in business processes accompanied with RFID implementation, a study in the radiology department of a major hospital network in Florida, estimated annual cost savings of around $18.33 \%$ over the earlier barcode systems (ÇAKICl; GROENEVELT; SEIDMANN, 2011).

${ }^{2}$ http://www.grandviewresearch.com/industry-analysis/rfid-kanban-systems-market 


\subsection{Operational advantages}

Operational Advantages include elimination of patient misidentification, reduction in procedural error, reduction in medication error, improvement of service efficiency, enhancement of workers' productivity, better resource utilization, reduction of clinical risk, proper time scheduling for the medical professionals, and so on. Unlike barcode scanning based periodic inventory review mechanisms, RFID enables adoption of continuous inventory review policy (ÇAKICl; GROENEVELT; SEIDMANN, 2011).

Thus, it paves the way to achieve greater patient satisfaction and consistent quality care assurance. The survey conducted by HIMSS (Healthcare Information and Management Systems Society) suggests that "Computerized Provider Order Entry" (CPOE) systems like bar code or RFID systems Management will be beneficial (PAUL, 2004). In this context, George Anderson, senior category manager, Leeds Teaching Hospitals NHS Trust, commented that "Top-up mechanisms vary from visual top-up in baskets through to bar-coded inventory control, with the Trust now looking into RFID stock control to identify and track movement of stock through the process"3.

\subsection{Management advantages}

From a management point of view, improved coordination among healthcare workforce is the main advantage of RFID deployment. Recently University Hospital in San Antonio incorporates RFID in their existing practice to devise an automated, improved workflow processes ${ }^{4}$. Also, improved patient satisfaction and quality assurance portrays a better image of management and stakeholders in social paradigm. In addition, higher operational efficiency facilitates management to get rid of additional costs regarding coordination, monitoring, tracking, etc.

\subsection{Barriers}

Exploration of literature suggests that there are several issues that can be major obstacles in the way of RFID implementation. These are demonstrated below:

$3 \quad$ http://www.healthcare-in-europe.com/en/article/10192-the-needs-of-europeanhospitals-are-similar.html

${ }^{4}$ http://www.mainspringhealth.com/rfid-journal-hospital-defines-its-problem-then-deploysrfid 
DOI: 10.14807/ijmp.v6i4.356

- Technological complexities

- High capital investment

- Privacy concern

\subsection{Technological complexities}

Ngai rightly identified that technological limitations of RFID can be an impediment to its successful deployment in the context of healthcare because of reliability concerns, operational complexity, adverse impact on the operations of medical devices, and lack of accepted industrial standards (NGAl et al., 2009). Due to lack of unified industry standards, RFID tags and their readers are prone to interference with critical medical devices like a pacemaker, etc.

Moreover, active RFID tags primarily due to their high costs and passive RFID tags due to their short range, have affected its slow adoption in the healthcare industry. Not just the hardware, the software aspects of this transition has also been impediments to its adoption. The underlying software infrastructure and archived data would need to be migrated from legacy barcode-based systems to the RFIDready system.

\subsection{High capital investment}

According to a healthcare study, integration costs of RFID lie between $\$ 10$ and $\$ 16$ million for a larger health care organization (HOSAKA, 2004). Also, high maintenance and upgradation cost related to the hardware, software, additional servers, databases, and middleware signifies the intensity of huge capital investment in RFID technology (THOMPSON, 2004). It dissuades health organizations to introduce RFID in their existing practice. Stakeholders of the healthcare organizations often maintain pessimistic stance to the adoption of RFID due to the huge initial capital expenditure and uncertainty of Return on investment often

\subsection{Privacy Concern}

Deployment of RFID systems gives rise to an ethical dilemma related to privacy concern (WICKS; VISICH; LI, 2006). When used for staff management, it raises concerns of constant movement tracking through RFID-based location tracking and strict monitoring protocols. RFID provides opportunities to marketers to develop their own database comprising the personal data of patient including not just 


\section{INDEPENDENT JOURNAL OF MANAGEMENT \& PRODUCTION (IJM\&P)}

http://www.ijmp.jor.br

v. 6, n. 4, October - December 2015

ISSN: 2236-269X

DOI: 10.14807/ijmp.v6i4.356

their medical data but also their identifiable social data and that too without even seeking for their permission.

Both implantable and externally attachable RFID tags allow monitoring of sensitive health parameters and permits the possibility of this information being shared with third parties. The access of sensitive private information using tags and tag readers raises concerns of surveillance and violation of basic privacy rights. Recently, the US Govt. had to publish a website release, related to Obamacare, in response to the public uproar about compulsory RFID implants and their perceived sharing of personal health data with the government ${ }^{5}$.

\section{DISCUSSION}

RFID brings many advantages in the domain of health care especially handling the issues related to asset management and patient service. However, successful implementation on a large scale depends on several critical factors like usability, scalability, availability, integration, interoperability, security, authorization, and sustainability maintenance expense (KUO; CHEN, 2008).

RFID implementation can be in the form of either replacement of conventional tracking technologies such as a barcode or as a novel application of technology instead of manual tracking processes. Both of these would need displacement of earlier organizational processes and thus its adoption would be governed by the minimality of the organizational transformation needed along with simplicity and adaptability of the new technology and the associated processes.

Technical errors regarding data reading and data storage can be detrimental to the patients' safety. Therefore, proper functioning of RFID tag plays a crucial role. Until now, most of the RFID systems are not compatible with the existing hospital digital system. Technical knowledge of health care professional to use RFID is not up to the standard. Often RFID system provided by the technology vendors is not compliant with the current medical regulation, thus leading to the higher clinical risk (FISHER; MONAHAN, 2008). The absence of clear and stringent industrial standard is another concern.

${ }^{5}$ https://obamacare.net/obamacare-chip/ 
INDEPENDENT JOURNAL OF MANAGEMENT \& PRODUCTION (IJM\&P)

http://www.ijmp.jor.br

v. 6, n. 4, October - December 2015

ISSN: 2236-269X

DOI: 10.14807/ijmp.v6i4.356

Rigorous technological tests should be conducted before the deployment of RFID in any healthcare organization. Collaboration between organizations and technology vendors can bring customizability as well as the compliance with the medical regulations. Proper knowledge management system and training programs should be conducted to educate the healthcare professionals about the appropriate usage of the technology.

Currently "Health Industry Business Communications Council (HIBCC)" is working on the establishment of common standards for healthcare system specialization with the help of International Organization for Standardization (ISO) and Electronic Product Code (EPC) standard. Health Insurance Portability and Accountability Act (HIPAA) can be instrumental in resolving the issues of privacy concern.

Several cases of success have been associated with RFID application in healthcare. Hospitals like Hospital St. Louis, the largest hospital in Luxembourg, Masaryk Oncological Institute in Czech Republic, and Wayne Memorial Hospital in USA have achieved better patient management, equipment tracking, better resource utilization, and better workforce management through the successful implementation RFID technology in healthcare ${ }^{6}$. For the sake of long-term benefit, small organizations are also showing interest in RFID adoption. Therefore, it is evident that the investment in RFID technology is rising.

\section{CONCLUSION AND FUTURE RESEARCH DIRECTION}

In this paper, we have proposed an integrated conceptual framework to represent different dimensions of RFID-enabled healthcare like functional aspects, barriers, and advantages. We demonstrate the key factors of successful deployment in the specific domain and current initiatives.

The deployment of RFID in healthcare offers a plethora of opportunities to the researchers and practitioners. For the sake of higher value creation in the context of the RFID-enabled healthcare value chain, there is a dire need to examine how process reengineering and modification is possible. Scholars have already mentioned that replacement of barcode scanning with RFID presents significant cost

\footnotetext{
${ }^{6}$ http://ehealth.eletsonline.com/2007/07/10993/
} 
INDEPENDENT JOURNAL OF MANAGEMENT \& PRODUCTION (IJM\&P)

http://www.ijmp.jor.br

v. 6, n. 4, October - December 2015

ISSN: 2236-269X

DOI: 10.14807/ijmp.v6i4.356

advantages when integrated with business process reengineering (ÇAKICl; GROENEVELT; SEIDMANN, 2011).

Also, future research needs to examine the impact of additional factors like the influence of stakeholders, the attitude of healthcare professionals and patients to the RFID integration. Privacy concerns regarding invasive RFID applications in healthcare has dampened the pace of its adoption. Studies aimed at recognition, conversance and mitigation of such issues shall help build a knowledge base accessible by both researchers and practitioners.

Cost-benefits analysis, ROI analysis for incorporating RFID technology into different areas like asset management, patient management, staff management, and process related issues should also be addressed in future scholarly works. The assessment related to the performance of RFID applications in different health care problems can be an area of interest for many researchers.

\section{REFERENCES}

ATTARAN, M. (2006) The coming age of RFID revolution. Journal of International Technology and Information Management, v. 15, n. 4, p. 77-88.

BAYSAN, S.; USTUNDAG, A. (2013) The Cost-Benefit Models for RFID Investments, In: The value of RFID. Springer London, p. 13-22.

BRADING, C. (2009) Counterfeits: Reducing the growing threat. Pharmaceutical Technology Europe, v. 21, n. 4, p. 36-40.

BRITTON, J. (2007) An investigation into the feasibility of locating portable medical devices using radio frequency identification devices and technology. Journal of medical engineering \& technology, v. 31, n. 6, p. 450-458.

ÇAKICI, Ö. E.; GROENEVELT, H.; SEIDMANN, A. (2011) Using RFID for the management of pharmaceutical inventory - system optimization and shrinkage control. Decision Support Systems, v. 51, n. 4, p. 842-852.

DEHORATIUS, N.; RAMAN, A. (2008) Inventory record inaccuracy: an empirical analysis. Management Science.

FISHER, J.; MONAHAN, T. (2008) Tracking the social dimensions of RFID systems in hospitals. International Journal of Medical Informatics, v. 77, n. 3, p. 176-183.

HONG, I. et al. (2011) An RFID application in the food supply chain: A case study of convenience stores in Taiwan. Journal of food engineering, v. 106, n. 2, p. 119126.

HOSAKA, R. (2004) Feasibility study of convenient automatic identification system of medical articles using LF $\square$ band RFID in hospital. Systems and Computers in Japan, v. 35, n. 10, p. 74-82. 
HOU, J.; HUANG, C. (2006) Quantitative performance evaluation of RFID applications in the supply chain of the printing industry. Industrial Management \& Data Systems, v. 106, n. 1, p. 96-120.

KATZ, J.; RICE, R. (2009) Public views of mobile medical devices and services: A US national survey of consumer sentiments towards RFID healthcare technology. International journal of medical informatics, v. 78, n. 2, p. 104-114.

$\mathrm{KIM}$, K. et al. (2008) Medical asset tracking application with wireless sensor networks, Proceedings - 2nd Int. Conf. Sensor Technol. Appl., SENSORCOMM 2008, Includes: MESH 2008 Conf. Mesh Networks; ENOPT 2008 Energy Optim. Wireless Sensors Networks, UNWAT 2008 Under Water Sensors Systems.

KOLESZAR, A. J. (2004) On drugs and distribution. Material Handling Management, v. 59, n. 1, p. 47-49.

KUO, C.; CHEN, H. (2008) The critical issues about deploying RFID in healthcare industry by service perspective, Proceedings of the 41st Annual Hawaii International Conference on System Sciences.

MEHRJERDI, Y. Z. (2010) RFID-enabled healthcare systems: risk-benefit analysis. International Journal of Pharmaceutical and Healthcare Marketing, v. 4, n. 3, p. 282-300.

NGAI, E. et al. (2009) Design of an RFID-based healthcare management system using an information system design theory. Information Systems Frontiers, v. 11, n. 4, p. 405-417.

ORANJE, C. VAN et al. (2009) Study on the requirements and options for Radio Frequency Identification (RFID) application in healthcare.

PAUL, E. (2004) Reengineering medication management from the bedside using bar-coding and wireless technology. HIMSS publication, v. 1, n. 12, p. 61-69.

PETERS, G.; PETERS, B. (2007) Medical error and patient safety: Human factors in medicine, CRC Press.

PULLEN, S.; ATKINSON, D.; TUCKER, S. (2000) Improvements in benchmarking the asset management of medical facilities, Proceedings of the International Symposium on Facilities Management and Maintenance, Brisbane.

RHODES, R.; RESNICK, A. (2005) Towards optimal surgical outcomes. Expert Review of Pharmacoeconomics \& Outcomes Research, v. 5, n. 6, p. 741.

SMITH, A. D. (2006) Evolution and acceptability of medical applications of RFID implants among early users of technology. Health marketing quarterly, v. 24, n. $1 / 2$, p. 121-155.

THOMPSON, C. (2004) Radio frequency tags for identifying legitimate drug products discussed by tech industry. American journal of health-system pharmacy: AJHP: official journal of the American Society of Health-System Pharmacists, v. 61, n. 14 , p. $1430-1432$.

TING, S. et al. (2011) Critical elements and lessons learnt from the implementation of an RFID-enabled healthcare management system in a medical organization.

Journal of medical systems, v. 35, n. 4, p. 657-669. 
INDEPENDENT JOURNAL OF MANAGEMENT \& PRODUCTION (IJM\&P)

http://www.ijmp.jor.br

v. 6, n. 4, October - December 2015

ISSN: 2236-269X

DOI: 10.14807/ijmp.v6i4.356

WAMBA, S. (2012) RFID-enabled healthcare applications, issues and benefits: An archival analysis (1997-2011). Journal of medical systems, v. 36, n. 6, p. 33933398.

WAMBA, S.; ANAND, A.; CARTER, L. (2013) A literature review of RFID-enabled healthcare applications and issues. International Journal of Information Management, v. 33, n. 5, p. 875-891.

WANG, B.; CHIANG, T. (2010) Applying RFID technology to develop a distant medical care service platform. International Journal of Electronic

BusinessManagement, v. 8, n. 2, p. 161.

WANG, S. et al. (2006) RFID application in hospitals: a case study on a demonstration RFID project in a Taiwan hospital, Proceedings of the Annual Hawaii International Conference on System Sciences.

WICKS, A.; VISICH, J.; LI, S. (2006) Radio frequency identification applications in hospital environments. Hospital topics, v. 84, n. 3, p. 3-9.

WOOD, C.; ALVAREZ, M. (2005) Emerging Construction Technologies: A FIATECH Catalogue, Fiatech, Construction Industry Institute, University of Texas,USA. Available:

$<$ https://scholar.google.co.in/scholar?q=+Emerging+Construction+Technologies+A+ Fiatech+Catalogue.\&btnG=\&hl=en\&as_sdt=0\%2C5\#0>. Access: 15/02/2015.

XIAO, Y. et al. (2006) Security and privacy in RFID and applications in telemedicine. Communications Magazine, IEEE, v. 44, n. 4, p. 64-72.

YAO, W.; CHU, C.; LI, Z. (2010) The use of RFID in healthcare: Benefits and barriers, Proceedings- IEEE International Conference on RFID-Technology and Applications (RFID-TA). 